\title{
Characteristic of QCM Coated Polystyrene and ZnPc Morphology Studied by AFM and SEM
}

\author{
Lalu A. Didik \\ Education Physics Departement, Faculty of Tarbiya and Education, Universitas Islam Negeri Mataram \\ Jalan Gajah Mada 100, Jempong Baru, Mataram, Indonesia.
}

\begin{abstract}
In this work, Quartz Crystal Microbalance (QCM) has been coating by Polystyrene (PS) and Zinc Phthalocyanine (ZnPc). This study aimed to examine the effect of coating using PS and $\mathrm{ZnPc}$ on the immobilization ability of QCM towards Bovine Serum Albumin (BSA) biomolecule. Polystyrene was used to coat the surface of QCM using Spin Coater technique, while $\mathrm{ZnPc}$ was coated by means of vacuum evaporation method. Surface characterization was performed using Scanning Electron Microscope (SEM) and Atomic Force Microscope (AFM), the QCM impedance was measured by using Impedance Analyzer; while the changes on its frequency was gauged by using frequency counter. Drawing on the SEM results, it was unveiled that PS layer was coated densely, while $\mathrm{ZnPc}$ was coated with full of roughness. The roughness of the PS and $\mathrm{ZnPc}$ layer was $244 \mathrm{~nm}$ and $88.9 \mathrm{~nm}$ respectively.
\end{abstract}

Keywords: QCM, biosensor, polystyrene, ZnPc

\section{INTRODUCTION}

Biosensor is an analytical device that draws on the employment of biomolecules (enzymes, tissues, cells, and microbe) to identify certain chemical substances through transducer of physic and chemistry. Biosensor can be classified into two categories, namely catalytic and affinity.

Affinity biosensor refers to a device that can detect immobilization of molecules through high selectivity. In its process, the compound is associated to the physic and chemistry changes and can be identified through transducer [1], [2].

A widely used transducer in the development of biosensor affinity is one based piezoelectric (Alexander et al., 2019; Asai et al., 2018). The former has some advantages, such as the ability to record compound reaction and its speed through the process of immobilization [5], [6]. One of the prominent piezoelectric biosensors is QCM [7]-[11].

On the surface of QCM is electrode that enable the presence of corrosion resulting in a lower sensitivity of the QCM. Hence, another non-corrosive material to cover its surface is needed, such as putting polystyrene over the surface of QCM [12]. In addition to its protective role in circumventing the corrosion, the layer made of polystyrene can immobilize proteins through physical absorption. Polystyrene plays a role as a matrix in biosensor, so it directly relates to analyses used in the biosensor [13]. Therefore, this research studied about morphology PS and $\mathrm{ZnPc}$ thin film on QCM surface.

\section{METHOD}

\section{A. Sample Preparations}

Before coated by polystyrene, initial frequency measurement of QCM was performed by means of frequency counter. The QCM was then coated by $50 \mu \mathrm{L}$ polystyrene solvent using spin coater. Subsequently, the QCM was annealed in an oven for about 2 hours with $100{ }^{\circ} \mathrm{C}$ temperature. After layered by polystyrene, the frequency of QCM was then measured to figure out the mass of per volume of the deposited polystyrene.

ZnPc was deposited on the QCM-polystyrene surface using the solidity evaporating technique (Robiandi et al., 2014). After the deposition of ZnPc on the surface of QCM/PS, the sample was then annealed for 12 hours with the temperature of $150{ }^{\circ} \mathrm{C}$ in an oven. The temperature level was deployed because $\mathrm{ZnPc}$ was still on a stable form and yet to experience a changing phase.

\section{B. AFM and SEM Characterization}

The data of SEM and AFM were adopted quantitatively to discover the morphological structure of thin layer deposited on the surface of QCM and damped factor of QCM analysed by means Impedance Analyzer.

The calculation of mass per volume of polystyrene layer drew on Sauerbrey equation formula,

$$
\Delta f=-2 \frac{f_{0}^{a}}{\sqrt{\rho_{q^{\mu} q}}} \frac{\Delta m}{A}
$$

To know the thickness of the polystyrene layer deposited on the surface of QCM, the second equation formula was employed [15].

$$
\Delta h=-\left[\frac{\Delta f}{f_{0}{ }^{2}}\right] 4206,5 \mathrm{~m}
$$

To measure the thickness of ZnPc layer deposited by using third equation [15].

$$
\Delta h=-\left[\frac{\Delta f}{f_{0}{ }^{2}}\right] 2944,61 \mathrm{~m}
$$




\section{RESULTS AND DISCUSSION}

Characterizing the morphology of polystyrene layer was performed by means of Scanning Electron Microscope (SEM). The morphology of polystyrene layer is shown in Figure 1a. The Figure illustrates that the immerging characteristics of thin polystyrene layer had porosity due to high value of young's modulus polystyrene. The greater the young modulus is, the stiffer the materials would become. Polystyrene has $3 \mathrm{GPa}$ value of young's modulus, which was higher compared to that of other polymers, such as polyurethane that possesses $3 \mathrm{MPa}$ value of young's modulus. The greater young's modulus caused higher porosity on the morphology of polystyrene layer. When being coated by means of spin coating technique, the centrifugal force would encourage wider layers that yield spaces during the coating [14], [15].

In this regard, the centrifugal force generated during the process of coating using the spin coating technique functions as strain force. However, because the characteristic of the polystyrene was stiff, the layer forced to more widely spread tended to experience plastic deformation. Because of this, the formed morphological layers will look like fractures and have cavities as depicted by the result of characterizing using SEM.

The quantitative analysis as shown in Figure $1 \mathrm{~b}$ showed that $\mathrm{ZnPc}$ deposited would initially fill in the porosities resulted by the polystyrene layer. This possibly happened because at glance the size of fibres layer of the $\mathrm{ZnPc}$ was smaller than the diameter porosity of the polystyrene layers [15].

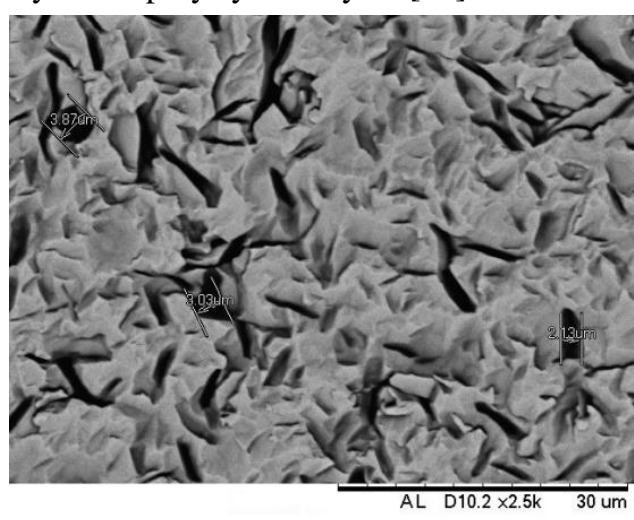

(a)
Characterizing by SEM indicated that the emergence of morphology of $\mathrm{ZnPc}$ layers in the form of fibres was empowered by using AFM characterization as shown in Figure 2. The Figure 2a represents the polystyrene layers depleted with cavities, which had greater roughness on the surface as evidenced in the Figure $2 \mathrm{~b}$. after coated by $\mathrm{ZnPc}$, the level of roughness was getting smaller in that it was covered by the $\mathrm{ZnPc}$ in the form of fibres evenly coating over the surface of polystyrene (see Figure $2 \mathrm{c}$ and $2 \mathrm{~d}$ ). This is the characteristics of stable phase structure $\beta \mathrm{ZnPc}$. For the annealed sample at $150{ }^{\circ} \mathrm{c}$, the fibres had diameter of $150 \mathrm{~mm}$ and length of 1 $\mu \mathrm{m}$, which caused the presence of empty spaces inside.

During the period of evaporation, the $\mathrm{ZnPc}$ materials that would be evaporated were leaving its source in the form gas. At the time, the atomic gasses were moving with the kinetic energy $3 / 2 \mathrm{kT}$ on the assumption that the steam of the $\mathrm{ZnPc}$ evaporated in the form of ideal gas would be in a vacuum space. Its directions would be uncontrollable and heap on the QCM/PS layer used as the target. Finally, the coating process would be formed after the atomic gasses underwent the process of condensation on the surface of substrate covered by the atomic gasses of the $\mathrm{ZnPc}$.

The condensation occurred during which the $\mathrm{ZnPc}$ atoms were adsorbed onto the surface of QCM/PS known as adsorption site. On each of the adsorption site, the immerging $\mathrm{ZnPc}$ atoms would be bound with certain adsorption energy. The Adsorption site with the highest adsorption energy was the stable place for the atoms.

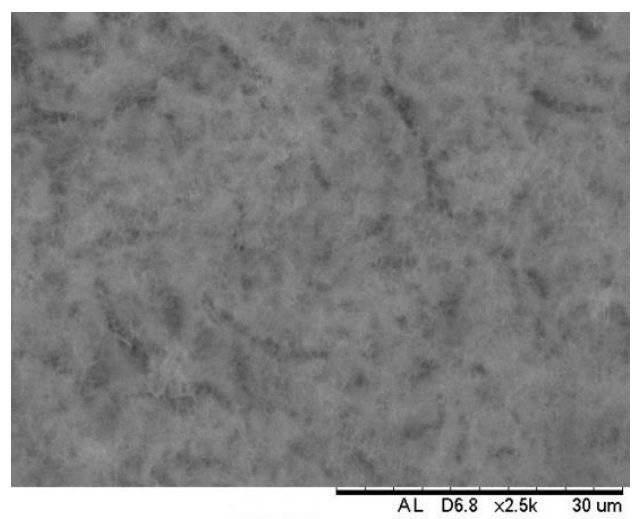

(b)

Fig. 1. Morphology of QCM Surface Characterized by SEM: (a) Polystyrene Coating, (b) ZnPc Coating.

Table 1. Surface Roughness of QCM Surface Characterized by AFM

\begin{tabular}{lcccc}
\hline \multicolumn{1}{c}{ Modification of QCM Surface } & \multicolumn{4}{c}{ Surface Roughness } \\
\cline { 2 - 5 } & $\mathrm{Sa}(\mathrm{nm})$ & $\mathrm{Sq}(\mathrm{nm})$ & $\mathrm{Ssk}$ & $\mathrm{Sz}(\mathrm{nm})$ \\
\hline Polystirene Coating & 244 & 320 & 0.408 & 2366 \\
ZnPc Coating & 88.9 & 117 & 0.261 & 760 \\
\hline
\end{tabular}




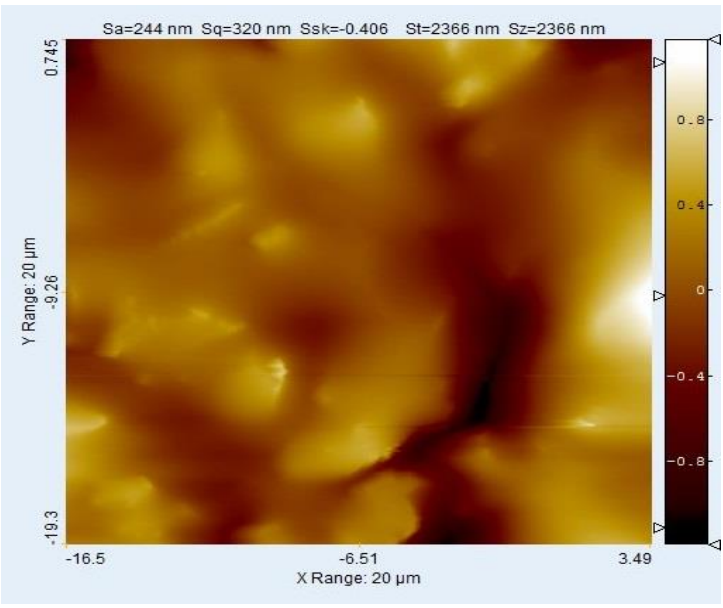

(a)

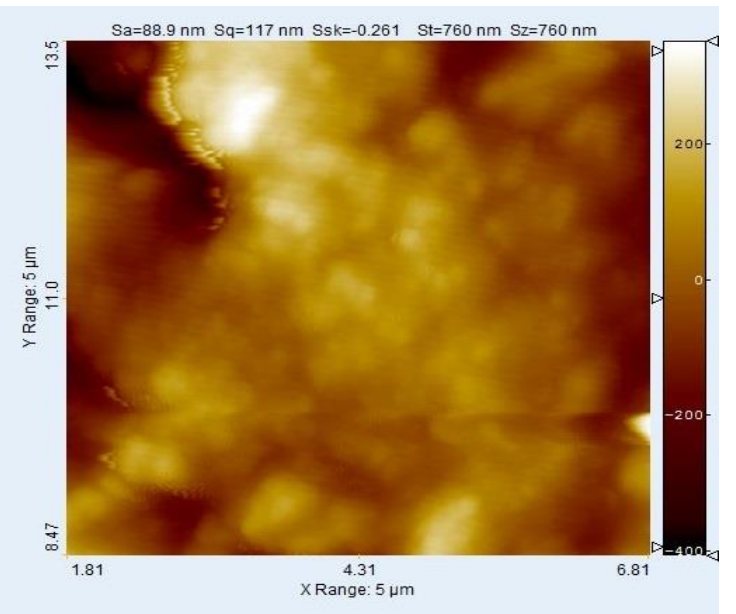

(c)

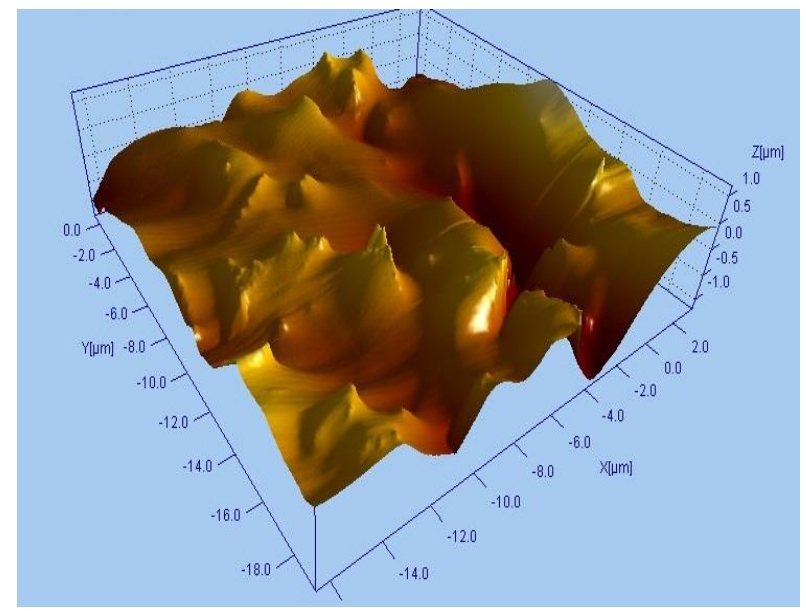

(b)



(d)

Fig. 2. Morphology of QCM Surface Characterized by AFM: (a) Polystyrene Coating, (b) Surface Roughness of QCM by Polystyrene Coating, (c) ZnPc Coating, (d) Surface Roughness of QCM by ZnPc Coating .

On the pressure level compatible to the evaporation, the $\mathrm{ZnPc}$ steam in the form of atoms appeared on the surface of polystyrene without losing the collision energy. After colliding, the ZnPc atoms attached themselves on the surface of the QCM/PS with weak binding force, which led to the tendency of leaving the outer parts of the substrate. It caused $\mathrm{ZnPc}$ layer has less surface roughness than PS layer that showed at table 1 .

Therefore, after performing the evaporation, the sample was annealed initially at the temperature of $150{ }^{0} \mathrm{C}$ for around 12 hours. The annealing alone could not alter the $\mathrm{ZnPc}$ phase because the maximum temperature for the $\beta \mathrm{ZnPC}$ phase is $200{ }^{\circ} \mathrm{C}$.

The Figure 3 illustrates the graph networking between the impedance and frequency as the output of the measurement by the impedance analyzer. Although the morphology of the thin layer was hollow, the thin layer generated remained in the condition of rigid body. Provided that the level of impedance was measurable, the thin layer yielded remained as rigid body; hence, the value of resonant frequency of QCM biosensor could be identified.

The electric characteristics of QCM could be categorized into certain equivalent RLC structure. For this reason, the correlation between impedance and frequency could be examined.

Table 2. QCM's Frequency Change because of PS and ZnPc Deposition

\begin{tabular}{lcc}
\hline Modification of & \multicolumn{2}{c}{ Characteristic } \\
\cline { 2 - 3 } QCM Surface & $\begin{array}{c}\text { Frequency } \\
\text { Change (Hz) }\end{array}$ & $\begin{array}{c}\text { Film } \\
\text { Thickness } \\
(\mathrm{nm})\end{array}$ \\
\hline Polystirene Coating & 11,339 & 476.3 \\
ZnPc Coating & 1,741 & 51.3 \\
\hline
\end{tabular}




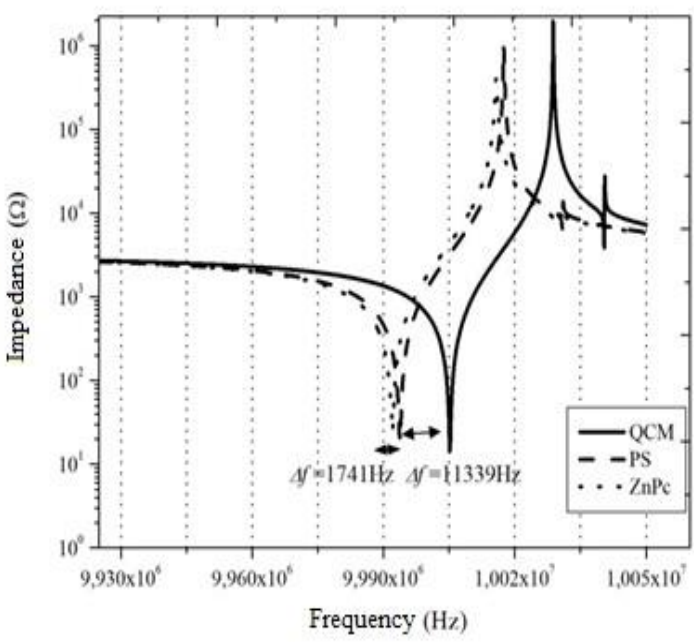

Fig. 3. Impedance Characteristic of QCM Biosensor

The characteristics of thin layer of both polystyrene and $\mathrm{ZnPc}$, which had porosity, significantly influenced the result of computation. The presence of the porosity resulted in the silence mechanic on the oscillator of QCM. The immergence of extra silence mechanic yielded higher values of impedance of oscillator QCM, which caused a failure for it to oscillate [2]. The significant changes on the frequency generated by the coating of Polystyrene and $\mathrm{ZnPc}$ and the thickness of the thin layer were presented in table 2 .

The added mass on the surface of QCM resulted in the adding value of inductance, which lowered the value of resonance frequency. Thus, on the impedance-frequency graph, the value of resonance frequency moved to the left side [13]. The changes on frequency was determined by calculating the range between resonance frequency of QCM before being coated by either polystyrene or ZnPc. Subsequently, drawing on the Saurbrey equation, the mass per unit of thin layer could be determined.

\section{CONCLUSION}

QCM refers to affinity biosensor that works based on the mass changes precipitated on its surface, so it can be deployed to immobilize biomolecule. To promote the amount of mass changes precipitated, polystyrene and Zinc Phthalocyanine coating was performed on the surface of QCM. Drawing on the characteristics of SEM and AFM, it was unveiled that the surface of polystyrene was rougher than that of the ZnPc. However, this did not cause over submerging for QCM as evidenced by the graph resulted from the analysis using Impedance Analyzer, which still indicated the highest resonance.

\section{ACKNOWLEDGMENT}

The author would like to thank the staff of Laboratories Material Universitas Brawijaya which helped provide facilities for synthesis and characterization QCM/PS and QCM/ZnPc biosensor.

\section{REFERENCES}

[1] S. P. Sakti, Masruroh, A. Sabarudin, D. J. D. H. Santjojo, and N. F. Khusnah, "Surface Modification of Polystyrene Coating on QCM Sensor using Ambient Air Plasma at Low Pressure," Mater. Today Proc., vol. 5, no. 7, pp. 15149-15154, 2018.

[2] A. Piñón-Pazos, J. L. Calvo-Rolle, B. A. Rodríguez-Gómez, J. L. Casteleiro-Roca, and M. C. Meizoso-Lopez, "New approach for the QCM sensors characterization," Sensors Actuators A Phys., vol. 207, pp. 1-9, 2014.

[3] N. Asai, T. Shimizu, S. Shingubara, and T. Ito, "Fabrication of highly sensitive QCM sensor using AAO nanoholes and its application in biosensing Author:," Sensors Actuators B. Chem., vol. 18, 2018.

[4] T. E. Alexander, L. D. Lozeau, and T. A. Camesano, "QCM-D characterization of time-dependence of bacterial adhesion," Cell Surf., vol. 5, no. March, p. 100024, 2019.

[5] H. J. Park and S. S. Lee, "A quartz crystal microbalance-based biosensor for enzymatic detection of hemoglobin A1c in whole blood," Sensors Actuators, B Chem., vol. 258, pp. 836-840, 2018.

[6] Masruroh et al., "Modification of polystyrene morphology and its influence to the coated zinc phthalocyanine layer and frequency change in QCM sensor," Mater. Sci. Forum, vol. 827, pp. 257-261, 2015.

[7] N. C. Speller, N. Siraj, S. Vaughan, L. N. Speller, and I. M. Warner, "QCM virtual multisensor array for fuel discrimination and detection of gasoline adulteration," Fuel, vol. 199, pp. 38-46, 2017.

[8] A. Karczmarczyk, K. Haupt, and K. H. Feller, "Development of a QCM-D biosensor for Ochratoxin A detection in red wine," Talanta, vol. 166, no. November 2016, pp. 193-197, 2017.

[9] L. Wang, Z. Wang, Q. Xiang, Y. Chen, Z. Duan, and J. Xu, "High performance formaldehyde detection based on a novel copper (II) complex functionalized QCM gas sensor," Sensors Actuators B. Chem., vol. 9, 2016.

[10]M. Deniz and H. Deligöz, "Flexible self-assembled polyelectrolyte thin films based on conjugated polymer: Quartz cristal microbalance dissipation ( QCM-D ) and cyclic voltammetry analysis," Colloids Surfaces A, vol. 563, no. December 2018, pp. 206-216, 2019.

[11]F. N. Dultsev and D. V Nekrasov, "Treatment of the resonance curve recorded during measurement of the signal of particle rupture from the QCM surface," Sensors Actuators B. Chem., 2018.

[12] Masruroh et al., Solvent effect on morphology of polystyrene coating and their role to improvement for biomolecule immobilization in application of QCM based biosensor, vol. 530-531. 2014.

[13]L. A. Didik, "Improvement QCM Quality by Polystirene Coating and Bovine Serum Albumin as Immobilization Agent," Al-Biruni, vol. 08, no. 1, pp. 35-41, 2019.

[14]F. Robiandi, L. A. Didik, E. Rahmawati, S. Rahayu, and S. P. Sakti, "Pengaruh Laju Deposisi Terhadap Morfologi Lapisan Zinc Phthalocyanine ( ZnPc ) di Atas Permukaan Polistiren / QCM dengan Proses Evaporasi Vakum," Nat. B, vol. 2, no. 4, pp. 336-342, 2014

[15]L. A. Didik, E. Rahmawati, F. Robiandi, S. Rahayu, and D. J. D. H. Santjojo, "Penentuan Ketebalan Lapisan Polistiren dan Zinc Phthalocyanine ( ZnPc) dengan Modifikasi Persamaan Sauerbrey dan Scanning Electron Microscope ( SEM )," Nat. $B$, vol. 2, no. 4, pp. 331-335, 2014. 